\title{
The effectiveness of cartographic visualisations in landscape archaeology
}

\author{
David Fairbairn $^{\mathrm{a}}$ \\ ${ }^{a}$ School of Civil Engineering and Geosciences, Newcastle University, NEWCASTLE UPON TYNE NE1 7RU, UK
}

\begin{abstract}
The use of maps and other geovisualisation methods has been longstanding in archaeology. Archaeologists employ advanced contemporary tools in their data collection, analysis and presentation. Maps can be used to render the 'big data' commonly collected by archaeological prospection techniques, but are also fundamental output instru-ments for the dissemination of archaeological interpretation and modelling. This paper addresses, through case studies, alternate methods of geovisualisation in archaeology and identifies the efficiencies of each.
\end{abstract}

Keywords: Geovisualisation, Landscape archaeology, map effectiveness

\section{Introduction}

Amongst the tasks of archaeology are the detection, identification, interpretation, analysis, explanation and presentation of data and information about man's traces on the environment over all periods of recorded history and, of course, earlier. Visualisation plays a crucial role in effecting such tasks, and the role of geovisualisation in this case, visualisation of the landscape, its artefacts, and archaeologists' study of these - is crucial.

The direct observation of the terrain and structures within it is central to the practice of landscape archaeology, and from the earliest surveys of the ancient archaeological record, mapping has been central to the discipline of archaeology. Exploration and field walking have been long-established methods of measuring and recording the landscape, and (as with topographic mapping itself) the use of aerial photography helped to advance archaeological investigation in the 20th century to previously unknown levels of intensity and rigour.

\section{History}

Even as recently as 1975, Figure 1, below, showing an image of a site with complex surface features, worthy of close investigation by landscape archaeologists, was described as the result of "a chance combination of air survey and a low winter sun (producing) a remarkable air photograph" (Roberts, 1975, p.48).

In the 21 st century the advances in geospatial data collection and in techniques of visualisation have progressed such that a new portfolio of images and maps are used and created by such investigators; and the possibilities of data integration through contemporary GIS to improve analysis and interpretation are routinely used.

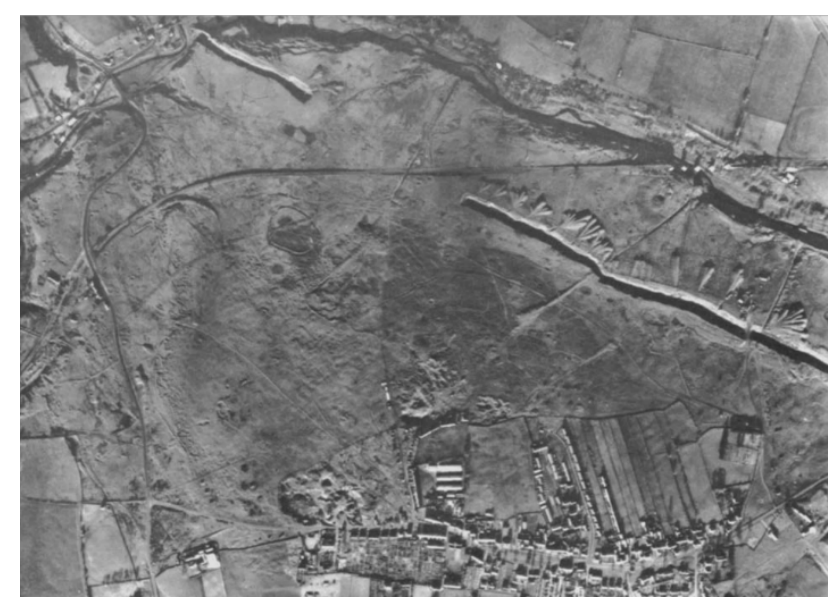

Fig. 1. Cockfield Fell aerial photograph 1971

\section{Mining archaeology}

Case study sites in England have been examined with the intention of assessing the effectiveness of different visualisations for rendering the nature of the landscape and for gaining 'added-value' from its representation. The two sites chosen exemplify surficial human mining and other activity in different time periods (from Neolithic to the 20th century) with their complex terrains comprising pits, spoil heaps, collapsed chambers, extraction channels, and related mining undertakings. Such features are manifest on traditional field survey plans, but much more comprehensively held within LiDAR datasets or derived digital surface models of the sites. The visualisation of such radically different data sources (including point clouds) and high resolution digital surface models (DSMs) has been examined to assess the improved effectiveness of contemporary displays for archaeological practice.

The first site to be examined is focused on the largest (in area, 350 ha.) scheduled ancient monument in England, Cockfield Fell in County Durham (northern England). There is evidence of occupation from the late Iron Age, when the main activity was agriculture, as it was throughout the Roman period. Coal mining was first 
mentioned in the 14th century, and whilst the predominant mineral, later extraction of sandstone and igneous roadstone took place alongside, into the second half of the 20th century. The terrain, and features on it, have been subject, therefore, to alteration and evident disturbance for two and a half millennia.

\section{Visualisation}

DSMs of Cockfield Fell were created from original one metre resolution airborne LiDAR data; and these were transformed into a number of terrain representations including contour diagrams, symbolised topographic maps, hill-shading and other image-based scenes, oblique views and fly-throughs. Further processing yielded other carto-graphic constructs of interest to archaeologists, such as 'sky-view' plots, ridge and channel maps, and principal components shading. These are all standard techniques based on i) cartographic experiences and best practice in terrain representation; ii) image processing by satellite remote sensing analysts; and iii) derivation of novel terrain indices by geomorphologists and surface scientists (Bennett et al., 2012; Doneus, 2013).

The results of such transformations for Cockfield Fell are shown in Figures 2 to 5, each of which gives an improved rendering of the terrain surface compared to the aerial photograph in Figure 1, and allows for more comprehensive interpretation of the surface archaeology. Unlike in the original aerial photograph, for example, individual bell pits (the primary means of extracting coal until the 19th century) are easily visible in the sky view plot (Figure 5), whilst the enclosures of native settlement immediately above locations A and B on the PCA plot (Figure 4) are evi-dent to a much higher degree.

The visualisation was enhanced further with the incorporation of geological mapping, particularly useful in the context of an investigation into historic mining, and clearly explaining the distribution of certain terrain artefacts (Figure 6).

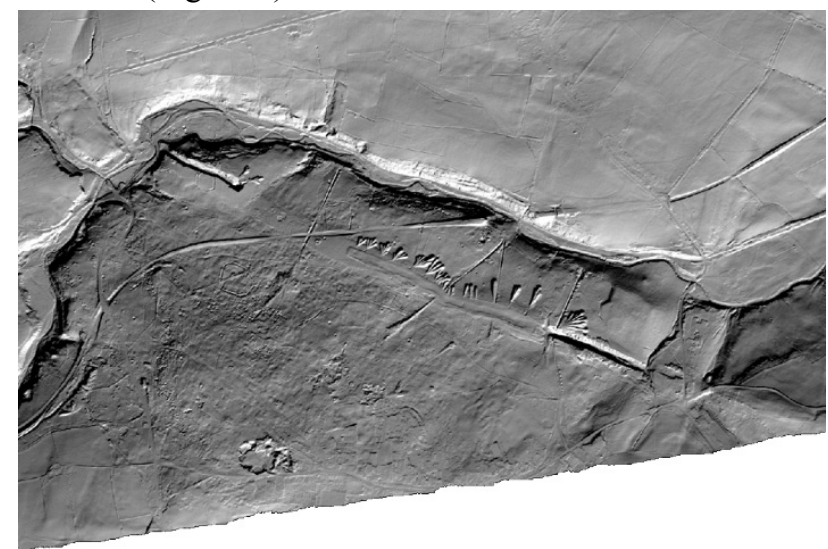

Fig. 2. Digital Surface Model derived from LiDAR: illumination azimuth 157.5 , elevation 45

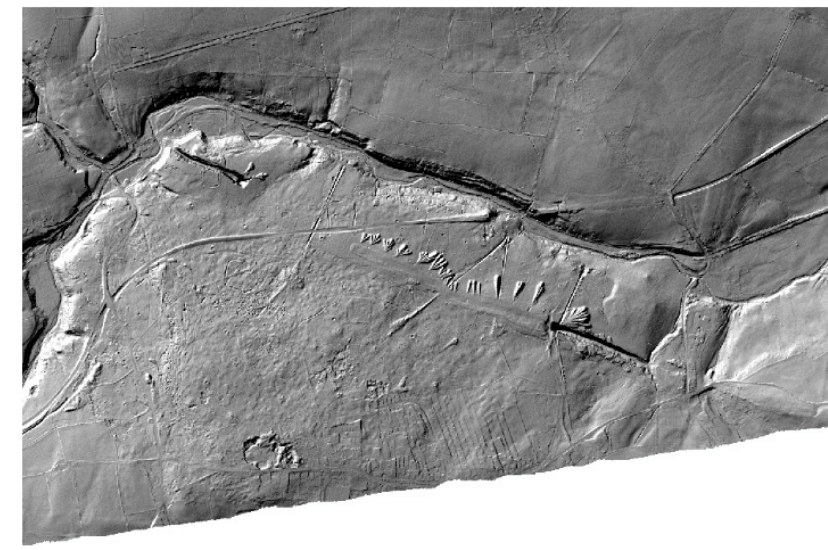

Fig. 3. Digital Surface Model derived from LiDAR: illumination azimuth 315 , elevation 45

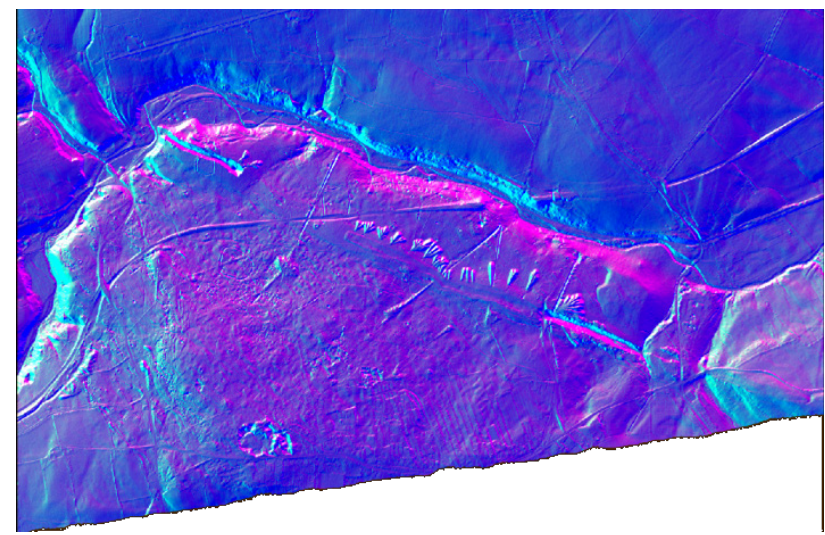

Fig. 4. Principal Components combination of illumination

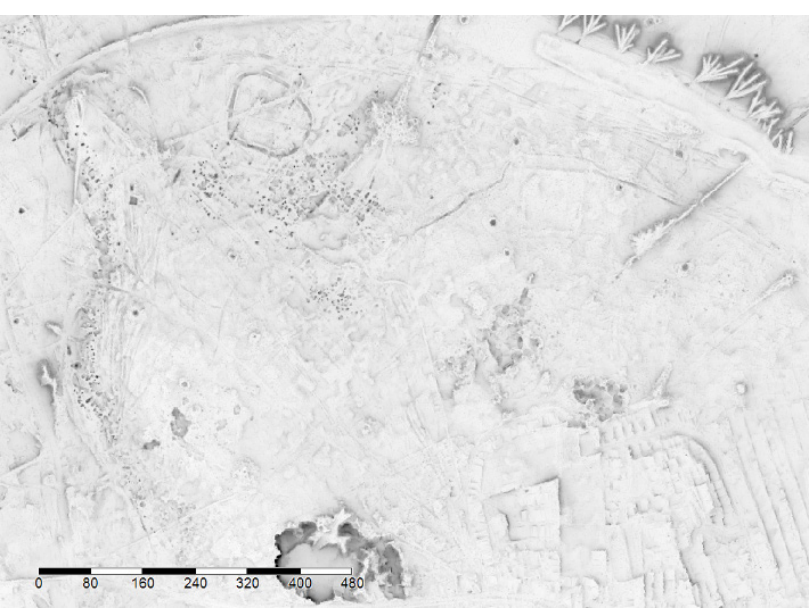

Fig. 5. Skyview of the central part of Cockfield Fell (scale in metres) 


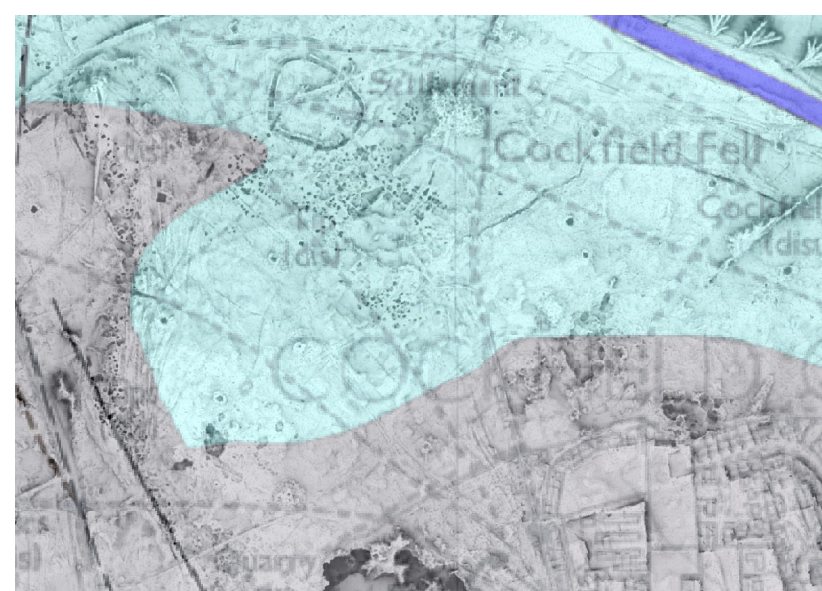

Fig. 6. Cockfield Fell sky view visualisation with geology overlay (exposure of grey-symbolised coal seam (Pennine Lower Coal measures) aligns to earlier, west-most bell pit distribution; later, deeper bell pits further east are sunk through surficial drift (Devensi-an)) [Geology data sourced from British Geological Survey 1:50,000 surficial geology series]

The visualisation of the terrain surface using these techniques has enhanced the limited amount of archaeological investigation which has been done on this landscape. The detection and identification of mining features has been relatively straightforward from such visualisations of Cockfield Fell. Further investigation of the more ancient human impact on the fell has also been pursued: the earlier identification of settlements as Iron Age ( 500 BC) - including locations A and C in Figure 4 - with the addition of a ( 500AD) Romano-British farmstead - location B - has been supplemented by confirmation that the area was never used for military activity during Roman occupation.

\section{Integration}

The integration of related mapping into the image visualisations as demonstrated for Cockfield Fell was further explored in the second case study site, focused on the nearby area of Blagill, near Alston, in Cumbria, northern Eng-land. This landscape also reflects its long history of extractive mineral exploitation, primarily involving lead and other metals, rather than coal (although coal measures are exploited within three km. of this site, even today: the other resources were tapped during a lengthy period from the 14 th century to the late 19 th century). The geology of this location is relatively straightforward, consisting of sedimentary layers of the Carboniferous era, including some with significant mineral resources, both in the rock and in mineralised veins. In the two sq. $\mathrm{km}$. area of interest, the so-called Stainmore formation comprises mudstone, sandstone and limestone, yielding rich ore deposits, whilst the nearby Firestone zone consists of relatively mineral-poor, uniform, sandstone. A large amount of waste resulted from mining operations and spoil heaps typify the landscape.

Closer examination of these geological zones revealed that the mining activity was, as expected, more concentrated in the Stainmore sedimentary outcrops than in the Firestone. Geological mapping was overlain on a
Digital Surface Model, derived from one metre resolution LiDAR airborne surveys (Figure 7).

Such simple overlay visually confirms that human activity, reflected in waste tips and mine digging is concen-trated in the Stainmore rock type, rather than the Firestone sandstone zone. GIS techniques were used to confirm this visual analysis: a number of derived metrics relating to comparative surface configurations were calculated for each zone. In addition, structural elements were extracted from the DSM.

Figure 8 shows that the metal bearing strata, the Stainmore Formation, showed higher levels of surface roughness than the Firestone Sandstone, and the density of gullies and peaks was higher in that zone also. The location and reconstruction, by archaeologists, of mining activity and an understanding of its impact on the landscape, can be assisted by such analysis.

In the context of such studies, the visualisation of other GIS-derived data outputs can be considered, ranging from presentation of terrain slope and aspect, to more complex measures such as fractal surface analysis (which may be difficult to interpret), and to three-dimensional derived artefacts such as viewsheds and predictive models. An eventual aim is to use the data and its visualisation to classify the mining remnants in the terrain by era and by function, and to enhance the study of comparative landscape archaeology across the sites.

Perhaps the most useful technique which can be brought to such landscape archaeology is the incorporation of time as a further dynamic visual variable. The actual embedding of a temporal coordinate into analysis is not straightforward, as it involves data collection and manipulation procedures which are difficult to standardise. Concepts of modelling and scenario-building which include a time dimension are applied in a rather ad hoc manner in contemporary GIS (Gupta and Devillers, 2016). In terms of visualisation, time is inherent both in the animated dis-play of sequences of map outputs and in the period within which a simulated 'fly-through' can be experienced. Such visualisation outputs have been derived from the datasets created for the case studies described: in the former case, the visualisation can replicate a dissemination of data which has been sourced (and refers to) sequential epochs; in the latter, a moving display which takes the viewer through a visualisation of a static environment can be constructed. 


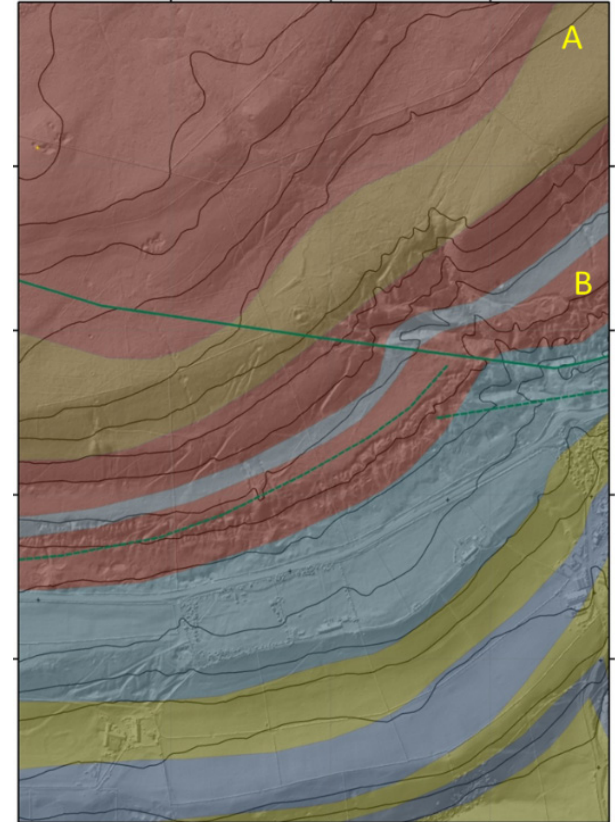

sionicoution ค"entoe seontoe octursol neeer insursise sneweresention

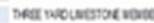

Fig. 7. Blagill DSM and geological mapping (grid ticks $200 \mathrm{~m}$ interval). A is Firestone Sandstone; B is Stainmore Formation

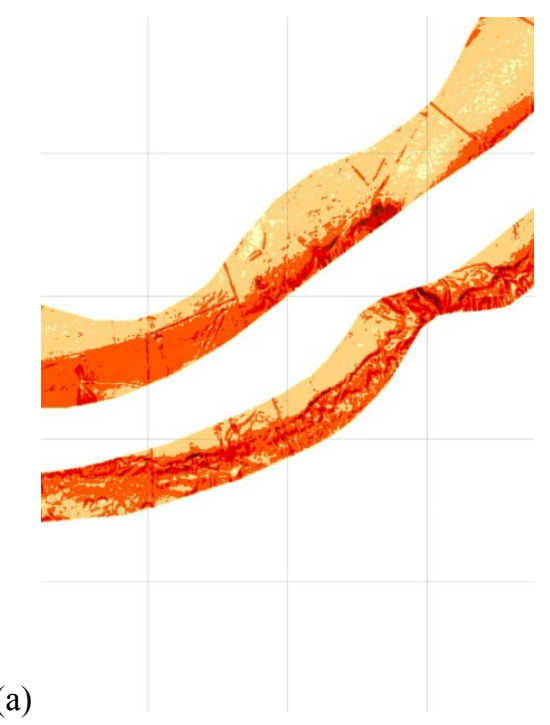

(b)

(c)

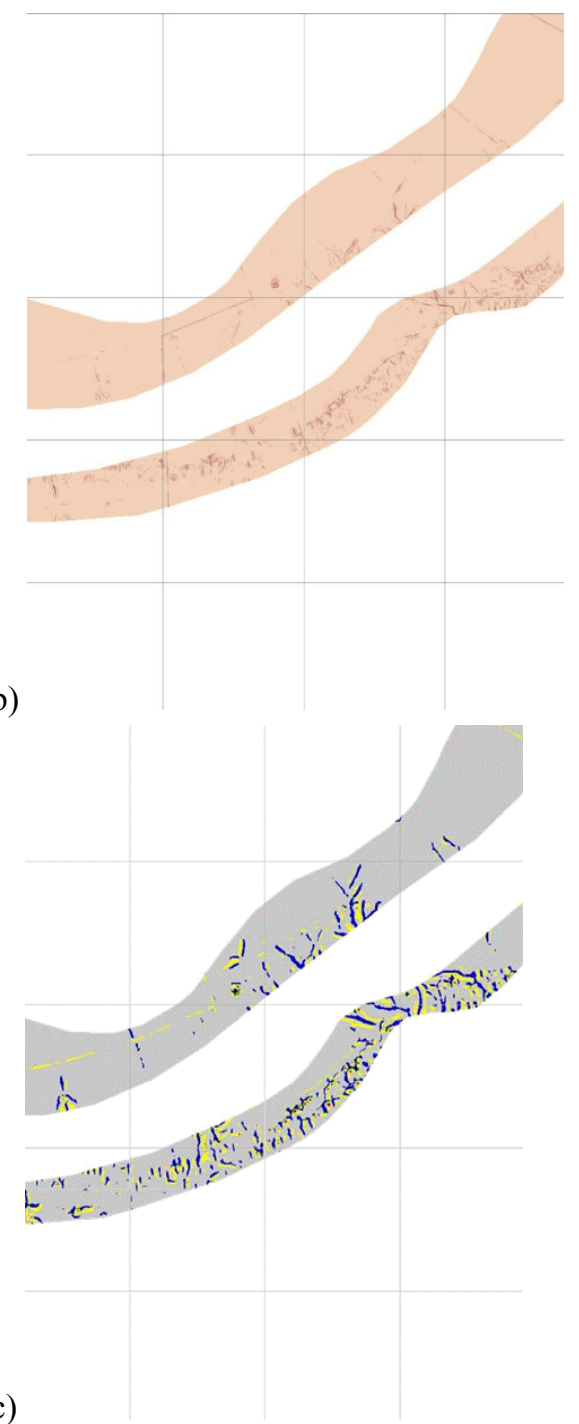

Fig. 8. (a) Terrain Ruggedness Index (b) Vector Ruggedness Index (c) structural elements (grid interval $200 \mathrm{~m}$ )

\section{Effectiveness}

A necessary task in the creation and dissemination of visualisations, including geovisualisations, maps, views, and fly-throughs, is the consideration of their effectiveness and value in use. A range of interactive observations, measurements, opinion gathering and testing can be undertaken to make an assessment of the success of visualisa-tion. Leading and valuable research has been undertaken in the cartographic community to promote and improve such forms of user-testing (Ooms, 2016). For this study, a user survey of experienced archaeologists and archaeolo-gy students has tested interaction and interpretation of a range of visualisations as described, for the purposes of detecting, identifying, and explaining. It is, as yet, uncertain whether users will prefer the generalised, object-based rendering of the landscape on a map (of numerous types), or a fly-through image capability, for the purposes of ar-chaeological investigation. Comparisons of the efficiency of contour maps with hill-shading of the same area, for example, were made by running task-specific tests on these user groups to check on data assimilation, interpretive insight, 
and knowledge acquisition. Figure 9 shows the value of standard contour mapping in identifying archaeological features on Cockfield Fell.

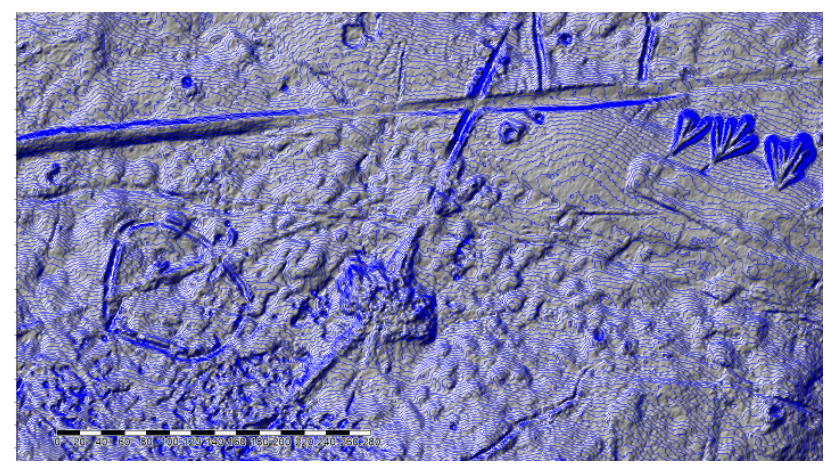

Fig. 9. Central Cockfield Fell: features in a dissected landscape rendered with $25 \mathrm{~cm}$ contours and hillshading

\section{Conclusion}

The work described here has been done in the context of a study on the detection and quantification of land-scape disorder (Fairbairn, 2015), but it also allows for the locating and reconstruction of mining activity by archaeologists. An assessment of the effectiveness of different cartographic visualisations has been undertaken. Such visualisations cover both the rendering of raw data, collected in a number of different ways, and the outputs from archaeological analysis, which show how visualisation can bring added-value to the tasks of archaeology.

The examination of traces and relics from human activity in the landscape is a core activity in archaeological study, as is the modelling and explanation of such activity. Using high-resolution terrain data and visualisation procedures, the long-standing collaboration between cartographers and archaeologists can be maintained and enhanced.

\section{References}

Bennett, R., Welham, K., Hill, R. and Ford, A. (2012) A Comparison of Visualization Techniques for Models Created from Airborne Laser Scanned Data. Archaeological Prospection 19, 41-48

Doneus, M. (2013) Openness as Visualization Technique for Interpretative Mapping of Airborne Lidar Derived Digital Terrain Mod-els. Remote Sensing 5, 6427-6442

Fairbairn, D. (2015) Mapping disorder: an exploratory study. Chapter 2 in Modern Trends in Cartography: Lecture Notes in Cartog-raphy and Geoinformation (eds. V.Vondrakova, J.Brus and V.Vozenilek) Springer, $13-22$

Gupta, N. and Devillers, R. (2016) Geographic Visualization in Archaeology. Journal of Archaeological Method and Theory doi:10.1007/s10816-016-9298-7

Ooms, K. (2016) Cartographic user research in the 21st century: mixing and interacting. Proceedings, 6th International Conference on Cartography and GIS, Albena, Bulgaria (eds. T.Bandrova and M.Konecny)

Roberts, B. (1975) Cockfield Fell. Antiquity 49 (193), $48-50$ 